\title{
A Continuing Medical Education Campaign to Improve Use of Antibiotics in Primary Care
}

\author{
Ronald S. Gibbs, ${ }^{1,2}$ Carolyn Wieber, ${ }^{1}$ Leslie Myers, ${ }^{2}$ and Timothy Jenkins ${ }^{3}$ \\ ${ }^{1}$ Office of Continuing Medical Education and Professional Development, University of Colorado Denver, 13001 East 17th Place, \\ C-295, Aurora, CO 80045, USA \\ ${ }^{2}$ Department of Obstetrics and Gynecology, University of Colorado School of Medicine, 12631 East 17th Avenue, MS 198-5, \\ Aurora, CO 80045, USA \\ ${ }^{3}$ Department of Internal Medicine, Denver Health, 660 Bannock Street, Denver, CO 80204, USA
}

Correspondence should be addressed to Ronald S. Gibbs; ronald.gibbs@ucdenver.edu

Received 25 February 2014; Accepted 13 May 2014; Published 25 May 2014

Academic Editor: Friedrich Paulsen

Copyright (C) 2014 Ronald S. Gibbs et al. This is an open access article distributed under the Creative Commons Attribution License, which permits unrestricted use, distribution, and reproduction in any medium, provided the original work is properly cited.

Because inappropriate use of antibiotics is common, it is an important area for continuing medical education. At an annual review, we conducted a two-year campaign to achieve appropriate use. Our methods included two surveys, directed course content, programmatic evaluation, and a sample practice audit. Ninety percent of learners perceived inappropriate antibiotic use as a "very big" or "big" problem in the United States, but only $44 \%$ perceived this about their practice $(P<0.001)$. Top perceived barriers to appropriate antibiotic use were patient expectations, breaking old habits, and fear that patients would go elsewhere. Top strategies to overcome these barriers were patient educational materials, having guidelines accessible, and developing practice policies. In a hypothetical patient with acute bronchitis, $98 \%$ would likely prescribe an antibiotic in certain clinical scenarios even though The Centers for Disease Control and Prevention does not recommend empiric antibiotic treatment. The most common scenarios leading to likely antibiotic prescription were symptoms over 15 days (84\%), age over 80 years (70\%), and fever (48\%). Practitioners are under multiple pressures to prescribe antibiotics even in situations where antibiotics are not recommended (such as acute bronchitis). To achieve complex practice changes such as avoiding inappropriate antibiotic use, no one strategy predominated.

\section{Introduction}

In contemporary continuing medical education, we recognize that education does not end in the classroom and that medical meetings alone are not likely to be effective for changing complex behaviors [1]. Multifaceted interventions are more likely to result from an educational campaign rather than from a single educational session $[2,3]$. In addition, Accreditation Council for Continuing Medical Education (ACCME) accreditation criteria for compliance require a continuing medical education (CME) provider "to integrate CME into the process for improving professional practice" (accreditation criterion 16), "identify factors outside the provider's control that impact outcomes" (accreditation criterion 18), and "implement educational strategies to remove, overcome, or address barriers to physician change" (accreditation criterion 19) $[4]$.
One practice area in the United States where improvement is needed is inappropriate use of antibiotics. Up to $48 \%$ of patients with rhinopharyngitis and up to $73 \%$ of patients with acute bronchitis are prescribed antibiotics even though these infections are generally not responsive to antibiotic therapy [5-8]. The Centers for Disease Control and Prevention (CDC) recommends against use of antibiotics in these clinical conditions [9].

As a consequence of inappropriate antibiotic prescribing, there is unnecessary expense and untoward sequelae including adverse drug reactions and selection pressure for resistant organisms [10-12]. The CDC has responded to the widespread problem of inappropriate antibiotic use by creating a campaign entitled "Get Smart" to educate providers and patients about appropriate use of antibiotics [9].

Despite the CDC campaign, inappropriate antibiotic prescribing in the United States remains alarmingly common 
[13]. Additional studies are needed to identify drivers of inappropriate antibiotic use, barriers to appropriate prescribing, and interventions to improve prescribing. Among primary care providers attending an annual review course, we conducted a two-year, multifaceted interactive campaign to educate providers regarding appropriate indications for antibiotic use, understand reasons why providers prescribed antibiotics inappropriately, and provide strategies to help overcome pressures to prescribe antibiotics for conditions where there is likely to be no benefit.

\section{Materials and Methods}

This research qualified as exempt research after review by the Colorado Multi-institutional Review Board.

For the past 60 years, the Office of Continuing Medical Education and Professional Development at the University of Colorado School of Medicine has produced a semiannual week long family medicine review. These courses attract primary care providers from around the country with approximately $70 \%$ being physicians and $30 \%$ nurse practitioners or physician's assistants.

2.1. 2012 Survey. At the 2012 sessions of the course, we asked learners to complete a four-question survey on paper. The first two questions asked them to estimate the importance of inappropriate antibiotic use as a problem in the United States and then in the individual's practice. The third question asked them to select the top three perceived potential barriers (from a menu of 18 items) to achieving appropriate antibiotic use. These perceived barriers were based on previous work of Price et al. [14, 15] and were used in our previous work [16]. The fourth question asked them to select the top three strategies (from a menu of 11 items) that they might realistically use to overcome the barriers. The potential strategies were based on those in previous work [16].

2.2. 2013 Survey. At the 2013 sessions of the course, we asked learners to complete a different four-question survey on paper. In this survey, the first question was whether the learner attended the 2012 Family Medicine Review conference. The second question was whether the learner had an outpatient practice. In the third question, we posed a hypothetical situation in which the respondent was evaluating an outpatient "with symptoms of acute bronchitis." We then asked which of the following symptoms or characteristics (from a menu of 10) would likely lead the practitioner to prescribe an antibiotic. The last question was whether the respondent had implemented any new strategies in the last year to avoid inappropriate use of antibiotics.

2.3. Course Content and Programmatic Evaluation. In addition to the surveys, there were several other elements in the campaign. In the 2012 review course, $12.5 \%$ (5 of 40) of the lecture or workshop sessions dealt with antibiotic use, and, in the 2013 review, $17.1 \%$ (7 of 41) of the sessions addressed antibiotic use. For one of the 2013 sessions, we included a workshop on dealing with patients who generally demand therapies. In both 2012 and 2013, we included one session as a "programmatic evaluation" in which we tallied the results of that year's survey and presented them at the end of the week. During these evaluation sessions, we engaged the learners regarding their additional insight into the survey findings and how they might decrease inappropriate antibiotic use.

2.4. Sample Practice Audit. In the 2012 survey, one of the top strategies identified to overcome inappropriate antibiotic use was a practice audit. Accordingly, in February and March 2013, we sought eight volunteer practitioners to conduct a short practice audit. We asked them to select five cases of acute rhinopharyngitis (also called nonspecific upper respiratory tract infection or the common cold) and five cases of acute bronchitis (also called acute cough illness). We asked that the cases be identified prior to determining whether antibiotics were used. We then asked the volunteer practitioners to identify patient age, gender, month of visit, and any comorbidities and whether an antibiotic was prescribed, and if so, the antibiotic and its duration. Practitioners were solicited by an e-mail sent in early February 2013 to all attendees of the 2012 courses, and eight practices were identified on a first-come first-serve basis. In order to maintain confidentiality from this small group of practices, we committed to the respondents that the results would not be published and would not be presented other than for discussion at the 2013 course.

2.5. Data Management and Statistical Analysis. We entered data from the paper forms into a Redcap database and used chi-square test to compare rates of discrete data, with $P$ value of less than 0.05 considered significant.

\section{Results}

3.1. 2012 Survey. At the 2012 course, the survey response rate was $64.9 \%$ (176 of 271 attendees). In Table 1, we show the replies to the two questions from the 2012 survey about perceived importance of the problem of inappropriate antibiotic use. Nearly $90 \%$ of respondents estimated the problem to be either "very big" or "big" in the United States. Although respondents estimated that inappropriate antibiotic use was significantly less of a problem in their own practices, still $44 \%$ perceived the problem to be either "very big" or "big" in their own practices $(P<0.001)$.

In Table 2, we show the replies to the question from the 2012 survey about the top barriers to appropriate antibiotic prescribing in primary care practice. Among the barriers identified, the most common one was patient expectations/patient agendas. Breaking old habits by provider and concern that patients would go elsewhere were ranked second and third. Only two respondents selected "No barriers." Overall, the barriers represented a complex combination of medical and interpersonal considerations, with no single barrier being identified by a majority of respondents.

Among the top strategies identified to reduce inappropriate antibiotic use, the most common was patient education and providing patient educational materials (Table 3 ). 
TABLE 1: Perceived importance of the problem of inappropriate antibiotic use, in the United States and in the individual's practice, by survey responders at University of Colorado, Family Medicine Review, 2012.

\begin{tabular}{lcc}
\hline Perceived importance of problem In the United States, number $(\%)(N=176)^{*}$ & In practice of survey responder, number $(\%)(N=176)^{*}$ \\
\hline "Very big" & $75(42.6 \%)$ & $11(6.25 \%)$ \\
"Big" & $83(47.2 \%)$ & $67(38.1 \%)$ \\
"Modest" & $18(10.2 \%)$ & $87(49.4 \%)$ \\
"Not a problem" & $0(0 \%)$ & $11(6.25 \%)$ \\
\hline
\end{tabular}

${ }^{*} P<0.001$ comparing responses in the United States to responses in individual practices.

TABle 2: Perceived barriers to achieving appropriate antibiotic use in responder's practice at University of Colorado, Family Medicine Review, $2012(N=538)^{*}$.

\begin{tabular}{lc}
\hline Barrier & $\begin{array}{c}\text { Number (\% of all } \\
\text { barriers identified) }\end{array}$ \\
\hline $\begin{array}{l}\text { Patient } \\
\text { expectations/agendas }\end{array}$ & $146(27.1)$ \\
$\begin{array}{l}\text { Breaking old habits } \\
\text { Fear that patients will go } \\
\text { elsewhere }\end{array}$ & $75(13.9)$ \\
Patient complexity & $65(12.1)$ \\
Worry about patient & $45(8.3)$ \\
complaints & $39(7.2)$ \\
Staff need more training & $29(5.4)$ \\
Appointment time & $29(5.4)$ \\
Medical-legal concerns & $20(3.7)$ \\
Patient adherence & $20(3.7)$ \\
Competing priorities & $14(2.6)$ \\
Need for additional skills & $12(2.2)$ \\
Relationships with other & $10(1.9)$ \\
physicians & $9(1.7)$ \\
Others & $8(1.5)$ \\
Staff competing priorities & $5(0.9)$ \\
Reimbursement & $3(0.6)$ \\
Organizational policies & $4(0.7)$ \\
$* *$ Remembering & $2(0.4)$ \\
No barriers &
\end{tabular}

*From a menu of 18 items plus "no barriers," each respondent was asked to select the top three. The total of responses averages about 3.06 per respondent because some gave more than 3 . We chose to include all selected responses.

${ }^{* *}$ Remembering: recalling what practice changes to make.

The second was having paper guidelines available to the practitioner, with a much smaller number of respondents identifying electronic links or "bookmarks." Of all strategies selected, education of patients, physicians, or staff accounted for 206 (40.7\%), whereas other practice interventions such as developing policies, conducting a practice audit, and holding staff meetings to discuss the problem collectively accounted for an additional $25.1 \%$ of all strategies selected. However, there was no single dominant strategy, speaking to the complexity of addressing inappropriate antibiotic use.

3.2. 2013 Survey. In the 2013 survey, the response rate was $56.7 \%$ (161 of 284). Overall, 35.4\% (57 of 161) had attended the 2012 Family Medicine Review, and $82.6 \%$ (133 of 161)
TABLE 3: Identified strategies to realistically use to overcome the barriers to appropriate antibiotic use, among survey responders at University of Colorado, Family Medicine Review, $2012(N=505)^{*}$.

\begin{tabular}{|c|c|}
\hline Strategy & $\begin{array}{c}\text { Number (\% of all } \\
\text { strategies identified) }\end{array}$ \\
\hline $\begin{array}{l}\text { Patient } \\
\text { education/educational } \\
\text { materials/information } \\
\text { sheets }\end{array}$ & $148(29.3)$ \\
\hline $\begin{array}{l}\text { Having paper copies of } \\
\text { guidelines }\end{array}$ & $73(14.5)$ \\
\hline Develop a practice policy & $56(11.1)$ \\
\hline $\begin{array}{l}\text { Practice audit to see how } \\
\text { my practice is doing }\end{array}$ & $55(10.9)$ \\
\hline $\begin{array}{l}\text { Signs in reception } \\
\text { area/office }\end{array}$ & $45(8.9)$ \\
\hline More physician education & $37(7.3)$ \\
\hline Longer appointment time & $24(4.7)$ \\
\hline More staff education & $21(4.2)$ \\
\hline $\begin{array}{l}\text { Accessing guidelines } \\
\text { electronically }\end{array}$ & $19(3.8)$ \\
\hline $\begin{array}{l}\text { Staff meeting to discuss this } \\
\text { problem }\end{array}$ & $16(3.2)$ \\
\hline Others & $11(2.1)$ \\
\hline
\end{tabular}

${ }^{*}$ From a menu of 11 strategies, each respondent was asked to select the top 3. The total of all responses averages about 2.87 because not all respondents selected 3. We chose to display all responses.

had an outpatient practice. Thus, there were 133 respondents who answered the question regarding symptoms likely to lead them to prescribe an antibiotic in evaluating an outpatient with symptoms of acute bronchitis (Table 4). Nearly all (131 of $133,98.5 \%)$ respondents indicated that they would likely prescribe an antibiotic for a patient who had at least one of the symptoms or characteristics. We observed high rates of antibiotic prescribing in the hypothetical scenarios of symptoms over two weeks (84\%) or among patients over 80 years $(70 \%)$. Moderately high rates of antibiotic prescribing were likely among patients with duration of symptoms of 8 to 14 days and among patients with fever (50\% and $48 \%$, resp.).

3.3. Programmatic Evaluation/Practice Audit. Because we informed the eight practitioners providing the audits that we would not publish the results, here we wish to comment only that the results of the audit provided an excellent source material for the discussions in the programmatic 
TABLE 4: Number of practitioners who would likely prescribe an antibiotic to an outpatient with symptoms of acute bronchitis, by presenting symptom or characteristic, among survey responders who had an outpatient practice, Family Medicine Review, 2013 ( $N$ = 133).

\begin{tabular}{lc}
\hline $\begin{array}{l}\text { Presenting symptom or } \\
\text { characteristic }\end{array}$ & $\begin{array}{c}\text { Number (\%) replying } \\
\text { they would prescribe } \\
\text { an antibiotic }\end{array}$ \\
\hline $\begin{array}{l}\text { Duration of symptoms for } \\
\text { over 21 days }\end{array}$ & $119(89.5)$ \\
$\begin{array}{l}\text { Duration of symptoms } \\
\text { 15-21 days }\end{array}$ & $112(84.2)$ \\
$\begin{array}{l}\text { Age greater than } 80 \text { years } \\
\text { Duration of symptoms 8-14 } \\
\text { days }\end{array}$ & $93(69.9)$ \\
$\begin{array}{l}\text { Fever } \\
\text { History of asthma } \\
\text { (controlled with inhaled } \\
\text { steroids) }\end{array}$ & $66(49.6)$ \\
$\begin{array}{l}\text { Age 65-80 years } \\
\text { Age less than one year }\end{array}$ & $64(48.1)$ \\
$\begin{array}{l}\text { Diabetes mellitus (well } \\
\text { controlled) }\end{array}$ & $54(40.6)$ \\
$\begin{array}{l}\text { Nonadherent patient } \\
\text { Expectoration of yellow } \\
\text { mucous }\end{array}$ & $49(36.8)$ \\
$\begin{array}{l}\text { Duration of symptoms for } 7 \\
\text { days }\end{array}$ & $43(32.3)$ \\
\hline
\end{tabular}

evaluation. In this programmatic evaluation, practitioners identified a number of strategies to deal with pressures to prescribe antibiotics when they are not indicated. Among these, one strategy was to lower patient anxiety by referring to the condition as a "chest cold" or by the CDC alternative designation as "acute cough illness." Another strategy was to provide symptomatic treatment, strong patient education, and a clear contingency plan such as to reevaluate the patient in 5 to 7 days if there was no improvement. Further insight was provided regarding clinical situations where practitioners might more commonly prescribe antibiotics for acute bronchitis. One of these was practice in a setting where there was no access to a chest radiograph. In such a practice setting, a provider could not rule out pneumonia, as recommended in selected circumstances, such as cough lasting 3 weeks or longer in absence of other known causes, by CDC guidelines [17].

Finally, in response to the question as to whether the practitioner had implemented any new strategy in the last year to avoid inappropriate use of antibiotics, $55.6 \%$ of those with an outpatient practice (74 of 133) indicated that they had. Of those who had also attended the 2012 course, 65.3\% (32 of 49) reported that they had implemented a new strategy compared with $50.0 \%$ (42 of 84 ) who had not attended the 2012 course $(P=0.086)$.

\section{Discussion}

In a two-year, multifaceted interactive campaign, we found that primary care providers widely perceived that inappropriate antibiotic use is a "very big" or "big" problem in the United States, but significantly fewer ones perceived that it was a problem of this importance in their own practices. In surveys, they identified multiple barriers to appropriate antibiotic use, including patient expectations, breaking their old habits, and fear that patients would go elsewhere. The most commonly selected strategies to overcome these barriers were patient education/educational materials, use of decision aides, developing practice policies, and practice audits. As part of our educational content, we included lectures and workshops not only on guidelines but also on dealing with patients who demand therapy. In programmatic evaluation sessions, we summarized the results of the surveys and engaged the learners with regard to how they might decrease inappropriate use of antibiotics. Our goal was to provide learners with a variety of tools to use when confronted with the common situation of feeling pressure to prescribe an antibiotic when antibiotic therapy is not indicated. One such frequent situation is acute bronchitis. Yet, because of the multiple pressures to prescribe antibiotics, a large percentage of practitioners succumb to these pressures and would likely prescribe an antibiotic, at least in some selected presentations (such as prolonged duration of symptoms, advanced age, and fever). Of survey responders who had attended both the 2012 and 2013 courses, $65 \%$ reported that they had instituted a strategy to improve antibiotic use in the last year compared with $50 \%$ of those who had not attended the 2012 course. However, this difference was not statistically significant $(P=0.086)$.

The results of our surveys are instructive as they demonstrated a variety of complex barriers to appropriate antibiotic prescribing. In addition, providers identified a number of interventions that may facilitate more appropriate prescribing; however, each was cited as likely to be effective by only a minority of providers. These results suggest that no single approach to assist providers in overcoming barriers and improving prescribing is likely to be impactful. Rather, multifaceted interventions are more likely to result in the desired change in prescribing practice, as has been shown in previous research $[2,3]$. The only modest impact of the CDC's multifaceted campaign to reduce inappropriate antibiotic use $[13]$ and recent interventional studies $[5,7]$ highlight that new strategies are needed to make more substantial progress.

Our findings from the hypothetical case of acute bronchitis were consistent with prior literature demonstrating a high rate of antibiotic prescribing $[5,7]$. Specifically, a large proportion of providers were likely to prescribe an antibiotic in older patients, those with fever, and those with prolonged duration of cough. Two recent randomized trials of antibiotics versus placebo for acute bronchitis demonstrated that patients treated with antibiotics had a similar time to resolution of symptoms but an increased frequency of adverse effects as compared with those receiving placebo $[18,19]$. In one study, there was no selective benefit in older patients [18]. Current CDC guidance does not advocate antibiotics for any subset of patients with acute bronchitis, 
although a cough for longer than three weeks should prompt an evaluation for alternative etiologies [9]. Our findings highlight the continued gap between provider practice and medical evidence/national guidelines and the need to continue to address inappropriate prescribing through patient and provider education and new interventions.

This work may have implications for CME practice. It is known that educational meetings are moderately effective in improving knowledge but poorly effective in changing complex behaviors [1]. Accordingly, for so complex area of practice as improving appropriate use of antibiotics - with all of its barriers and with so many potential strategieswe instituted a multifaceted campaign among learners at consecutive annual free-standing review courses. In 2012, we were able to sequentially determine how learners perceived the importance of the problem, what barriers there were, and what strategies might realistically be implemented. In 2013, we focused on a common problem area in practiceacute bronchitis-where empiric antibiotics are commonly prescribed even though not recommended. We also determined reported implementation of new practice strategies in the last year to improve antibiotic use. As this was a free-standing CME activity with practitioners from a broad geographic area, we are not able to assess the effectiveness of this campaign in terms of actual improvement in practice. However, we did observe that those who had attended both courses were somewhat more likely (65\% versus $50 \%$ ) to have reported instituting a new strategy within the last year to improve practice, although this difference did not achieve significance $(P=0.086)$.

We recognize several limitations to this work. First, the response rate was moderate (56-65\%) in the two surveys, and we do not know how survey responders differ from nonresponders. Second, we acknowledge that in all surveys the replies are those reported and not necessarily (as in the question about acute bronchitis) what is actually done in practice. Third, our sample size in the questionnaires is modest, perhaps creating a beta error as in the association between having reported a practice change in the last year to improve antibiotic use and having attended the previous year's course.

In CME activities such as a regularly scheduled series (RSS) involving a rather fixed set of leaners and with access to quality data, there would be a better opportunity to test the effectiveness of such a campaign. Indeed, performance improvement CME activities and the new multispecialty Maintenance of Certification Portfolio Approval Program (http://mocportfolioprogram.org/) are excellent examples of how to use CME in a campaign to improve practice. However, even in free-standing courses, we encourage CME providers to experiment with multiyear, multifaceted interactive campaigns on high impact areas in order to improve practice.

\section{Conclusions}

Effecting complex practice changes such as avoiding inappropriate use of antibiotics is a prime area for continuing medical education. Learners widely perceived the importance of the problem of inappropriate antibiotic use in the United States, but significantly fewer ones perceived this was an important problem in their own practices. In addition to direct educational content on national guidelines for antibiotic use, additional parts of the educational campaign dealt with identification of barriers and of strategies to overcome these barriers. To achieve complex practice changes, no one single strategy predominated.

\section{Conflict of Interests}

The authors declare that there is no conflict of interests regarding the publication of this paper.

\section{References}

[1] L. Forsetlund, A. Bjørndal, A. Rashidian et al., "Continuing education meetings and workshops: effects on professional practice and health care outcomes," Cochrane Database of Systematic Reviews, no. 2, Article ID CD003030, 2009.

[2] L. A. Bero, R. Grilli, J. M. Grimshaw, E. Harvey, A. D. Oxman, and M. A. Thomson, "Closing the gap between research and practice: an overview of systematic reviews of interventions to promote the implementation of research findings," British Medical Journal, vol. 317, no. 7156, pp. 465-468, 1998.

[3] J. M. Grimshaw, L. Shirran, R. Thomas et al., "Changing provider behavior: an overview of systematic reviews of interventions," Medical Care, vol. 39, no. 8, supplement 2, pp. II2II 45, 2001.

[4] Accreditation Council for Continuing Medical Education: Accreditation Criteria, http://www.accme.org/requirements/ accreditation-requirements-cme-providers/ accreditation-criteria.

[5] R. Gonzales, T. Anderer, C. E. McCulloch et al., "A cluster randomized trial of decision support strategies for reducing antibiotic use in acute bronchitis," JAMA Internal Medicine, vol. 173, no. 4, pp. 267-273, 2013.

[6] R. Gonzales, D. C. Malone, J. H. Maselli, and M. A. Sande, "Excessive antibiotic use for acute respiratory infections in the United States," Clinical Infectious Diseases, vol. 33, no. 6, pp. 757$762,2001$.

[7] T. C. Jenkins, A. Irwin, L. Coombs et al., "Effects of clinical pathways for common outpatient infections on antibiotic prescribing," American Journal of Medicine, vol. 126, no. 4, pp. 327.e12-335.e12, 2013.

[8] M. A. Steinman, C. S. Landefeld, and R. Gonzales, "Predictors of broad-spectrum antibiotic prescribing for acute respiratory tract infections in adult primary care," The Journal of the American Medical Association, vol. 289, no. 6, pp. 719-725, 2003.

[9] The Centers for Disease Control and Prevention: Get Smart for Healthcare, http://www.cdc.gov/getsmart/healthcare/.

[10] N. Shehab, P. R. Patel, A. Srinivasan, and D. S. Budnitz, "Emergency department visits for antibiotic-associated adverse events," Clinical Infectious Diseases, vol. 47, no. 6, pp. 735-743, 2008.

[11] L. Sun, E. Y. Klein, and R. Laxminarayan, "Seasonality and temporal correlation between community antibiotic use and resistance in the United States," Clinical Infectious Diseases, vol. 55, no. 5, pp. 687-694, 2012.

[12] A. Gallini, E. Degris, M. Desplas et al., "Influence of fluoroquinolone consumption in inpatients and outpatients on 
ciprofloxacin-resistant Escherichia coli in a university hospital," Journal of Antimicrobial Chemotherapy, vol. 65, no. 12, pp. 26502657, 2010.

[13] L. F. McCaig, L. A. Hicks, R. M. Roberts, and T. A. Fairlie, "Office-related antibiotic prescribing for persons aged $\leq 14$ years-United States, 1993-1994 to 2007-2008," Morbidity and Mortality Weekly Report, vol. 60, no. 34, pp. 1153-1156, 2011.

[14] D. W. Price, E. K. Miller, A. K. Rahm, N. E. Brace, and R. S. Larson, "Assessment of barriers to changing practice as CME outcomes," Journal of Continuing Education in the Health Professions, vol. 30, no. 4, pp. 237-245, 2010.

[15] D. W. Price and K. G. Felix, "Journal clubs and case conferences: from academic tradition to communities of practice," Journal of Continuing Education in the Health Professions, vol. 28, no. 3, pp. 123-130, 2008.

[16] R. Gibbs and D. W. Price, "Intended practice changes and barriers among primary care providers," CE Measure, vol. 6, pp. 49-52, 2012.

[17] Centers for Disease Control and Prevention (CDC), "Get Smart, Acute Couch Illness (Acute Bronchitis)," http://www.cdc.gov/ getsmart/campaign-materials/info-sheets/adult-acute-coughillness.pdf.

[18] P. Little, B. Stuart, M. Moore et al., "Amoxicillin for acute lowerrespiratory-tract infection in primary care when pneumonia is not suspected: a 12-country, randomised, placebo-controlled trial," The Lancet Infectious Diseases, vol. 13, no. 2, pp. 123-129, 2013.

[19] C. Llor, A. Moragas, C. Bayona et al., "Efficacy of antiinflammatory or antibiotic treatment in patients with noncomplicated acute bronchitis and discoloured sputum: randomised placebo controlled trial," British Medical Journal, vol. 347, Article ID f5762, 2013. 

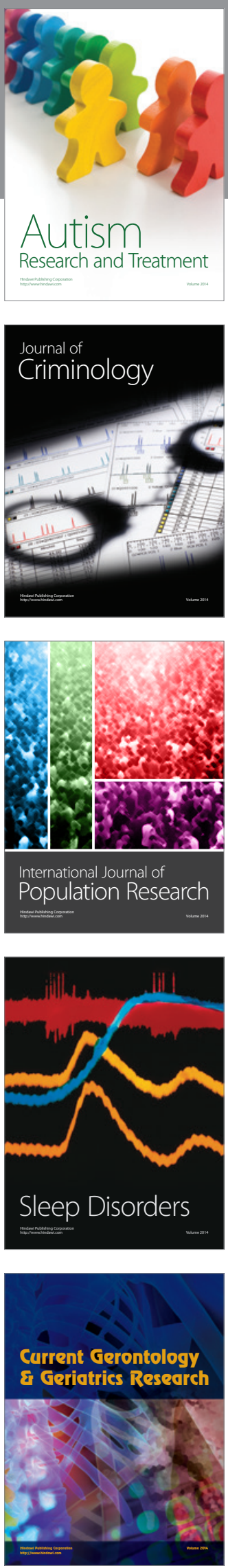
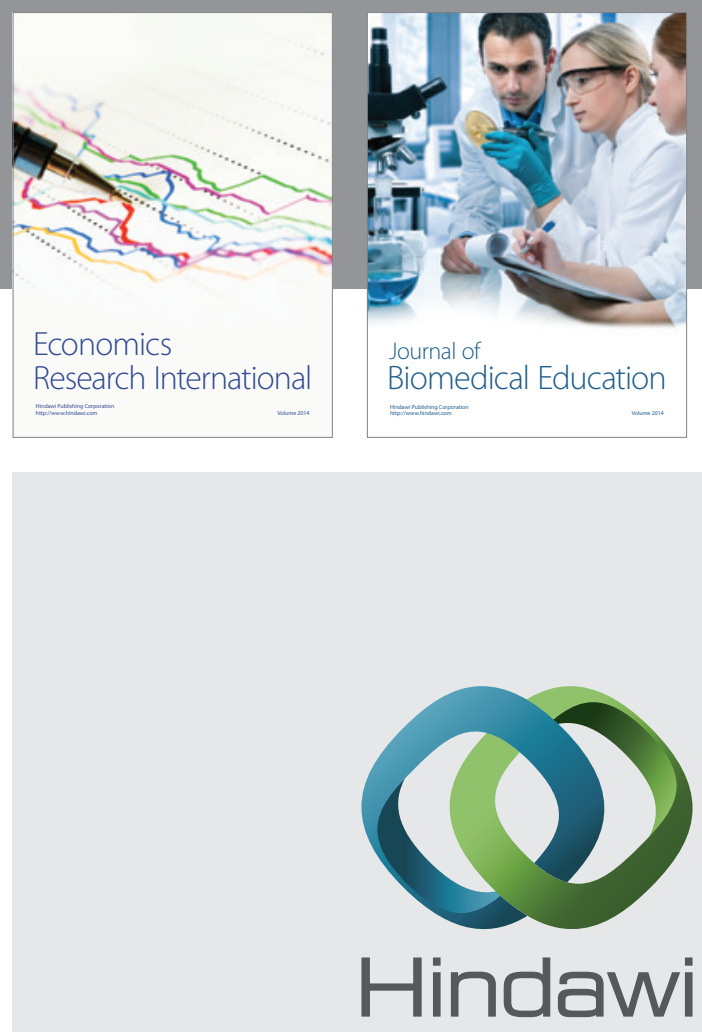

Submit your manuscripts at

http://www.hindawi.com
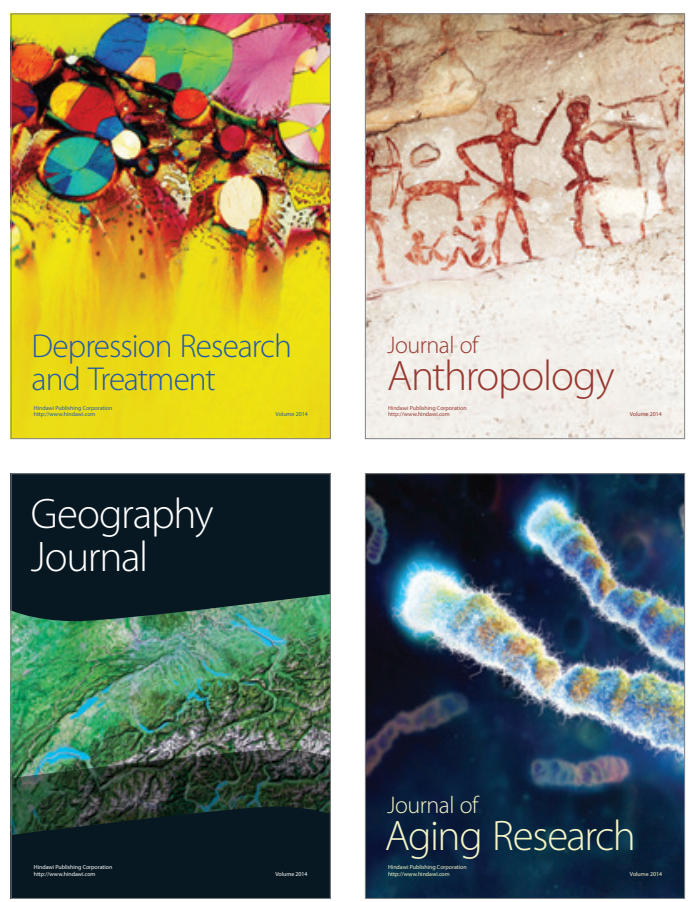
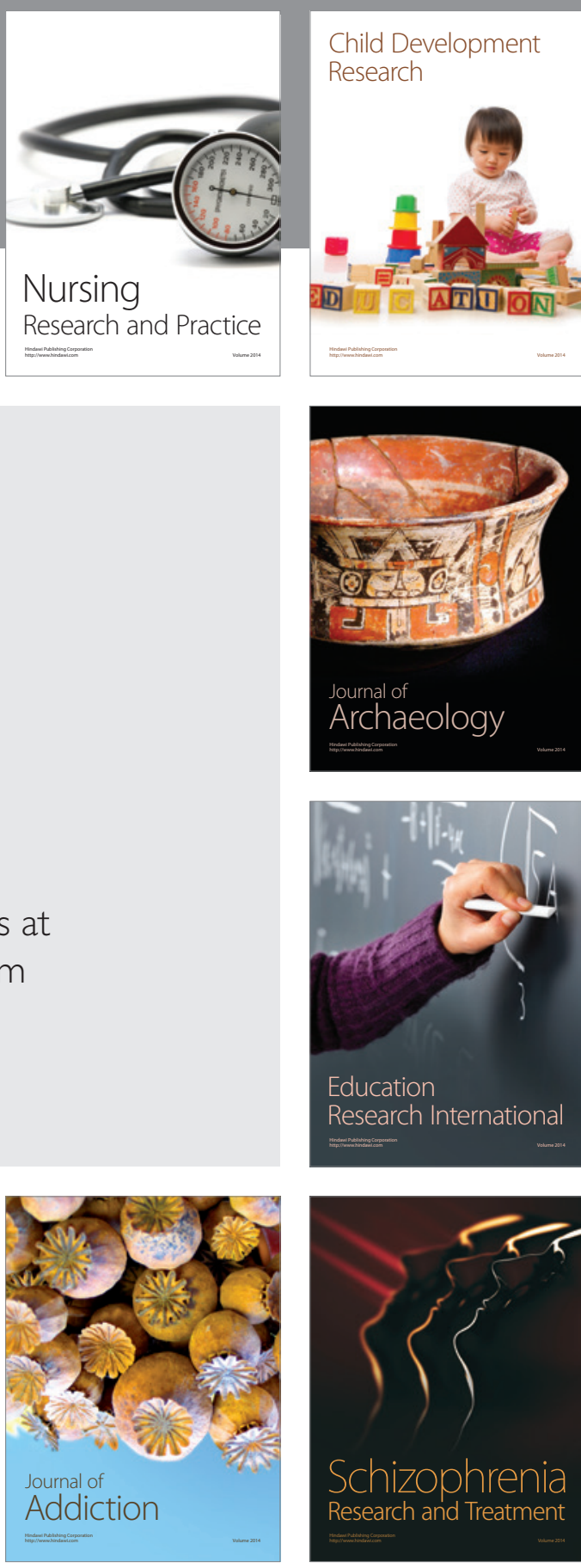

(D)
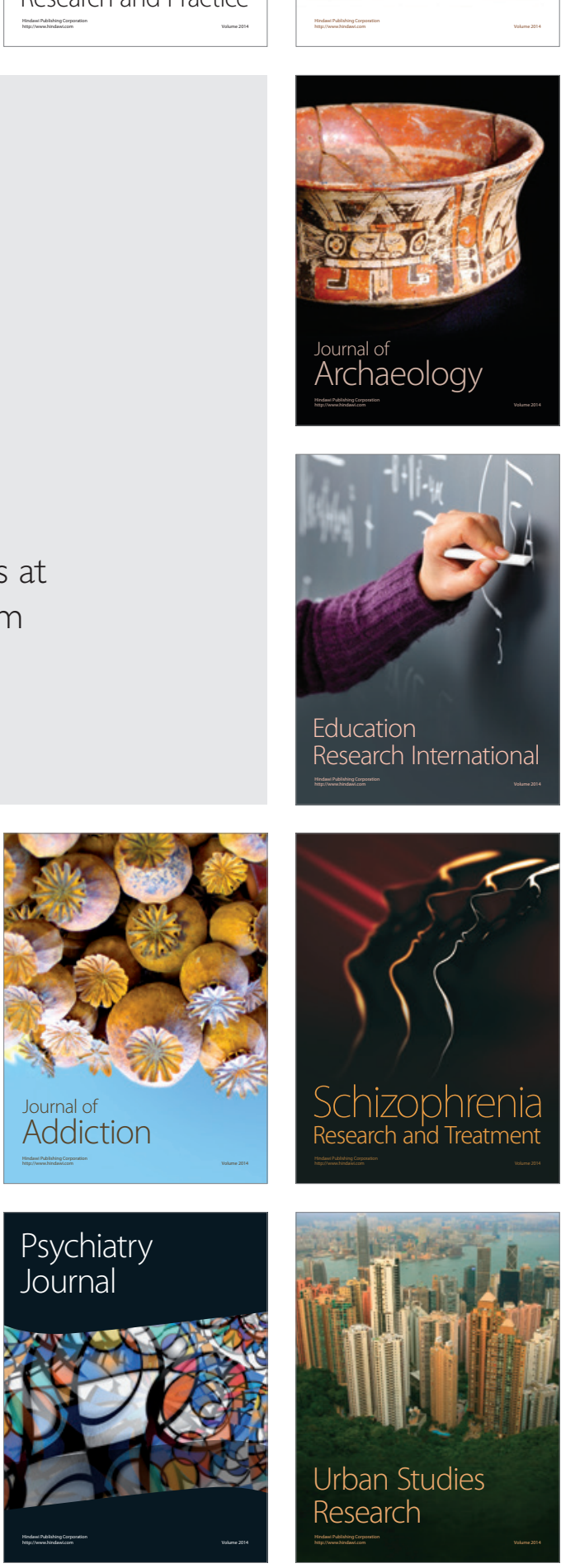